\title{
Application of Assessment Tools to Examine Mental Health in Workplaces: Job Stress and Depression
}

\author{
Sang Won Jeon ${ }^{1}$ and Yong-Ku Kim ${ }^{2}$ \\ 1'Department of Psychiatry, Kangbuk Samsung Hospital, Sungkyunkwan University School of Medicine, Seoul, Republic of Korea \\ ${ }^{2}$ Department of Psychiatry, Korea University Ansan Hospital, Korea University College of Medicine, Ansan, Republic of Korea
}

Despite the fact that the lifetime and yearly prevalence rates of mental illness continue rising, such diseases have only been acknowledged as involved in workplace health issue since the 2000s. Additionally, while the number of recognized cases of mental illnesses is rather low compared to their prevalence, they have a high likelihood of causing significant problems, including fatalities. Many workers are terrified of losing their jobs due to mental illness and therefore attempt to hide their mental health problems. For this reason, clinicians involved in occupational and environmental medicine should focus on interviews or screenings to identify such hidden mental health problems. More specifically, it would be helpful to evaluate job stress and depression in workplaces to ensure appropriate preventive actions and thereby reduce the prevalence of mental illness. Job stress not only causes mental illness and dissatisfaction with work, but also can increase the prevalence and morbidity of medical diseases, as well as other physical health problems. Depression is a major contributor to work loss and absence with effects surpassing almost all of the chronic medical disorder. These facts show why measure of job stress and depression should be highlighted in the occupational settings. This article introduces a variety of assessment tools to examine mental health, particularly stress and depression, in workplaces. These tools can be used by clinicians or professionals involved in the mental health, occupational safety, or health service fields for running diagnostics or screening tests.

Psychiatry Investig 2018;15(6):553-560

Key Words Rating scale, Work place, Mental health, Job stress, Depression.

\section{INTRODUCTION}

Despite the fact that the lifetime and yearly prevalence rates of mental illness continue to rise, they have only been recognized as being involved in workplace incident since the 2000s. ${ }^{1,2}$ According to a report called "Statistics of Industrial Accidents," published in 2013, ${ }^{3}$ there were a total of 33 cases wherein mental disorders were recognized as being work-related. This accounts for $0.49 \%$ of all work-related diseases. Examining the mortality rate for work-related diseases in this report reveals that 20 cases were caused by mental illness, or $2.38 \%$ of all deaths. ${ }^{3}$ As such, compared to their prevalence, there appear to be few recognized cases of mental illness,

\footnotetext{
Received: June 24, 2016 Revised: August 24, 2016

Accepted: October 24, 2016

$\triangle$ Correspondence: Yong-Ku Kim, MD, PhD

Department of Psychiatry, Korea University Ansan Hospital, Korea University College of Medicine, 123 Jeokgeum-ro, Danwon-gu, Ansan 15355, Republic of Korea

Tel: +82-31-412-4930, Fax: +82-31-412-5144, E-mail: yongku@korea.ac.kr

(c) This is an Open Access article distributed under the terms of the Creative Commons Attribution Non-Commercial License (http://creativecommons.org/licenses/by$\mathrm{nc} / 4.0$ ) which permits unrestricted non-commercial use, distribution, and reproduction in any medium, provided the original work is properly cited.
}

whereas their possibility of causing significant problems, including fatalities, appears high.

Despite not being a nationally representative survey, a study on 254 businesses (6,977 workers) conducted in 2001 indicated that only $5 \%$ of subjects showed healthy levels of stress. ${ }^{4}$ In contrast, $73 \%$ fit into the potential stress group and $22 \%$ the high-risk stress group, thus signifying that most workers are exposed to stress. ${ }^{4}$ Job stress not only causes mental illness (e.g., depression) and dissatisfaction with work, but also can increase the prevalence and morbidity of hypertension or other cardiovascular diseases, as well as other physical health problems such as musculoskeletal disease, gastric ulcers, or others. ${ }^{2.5}$ Therefore, it is important to measure and manage job stress in the workplace.

According to statistics on the usage of medical services (from a report called the "Epidemiologic Survey on Mental Diseases" in 2010), $15.3 \%$ of individuals who have experienced a mental illness actually ended up visiting a doctor. ${ }^{6}$ The statistics on the usage of medical services reflect whether an individual used a needed medical service at least once or more in his/her entire lifetime. Therefore, the number of patients who 
receive the appropriate medical care for their illness can be expected to be even lower. Workers are no exception, and this results in a tremendous number of hidden patients with depression and other mental illnesses. ${ }^{2}$

In the working population, approximately $2 \%$ to $4 \%$ of workers suffer from major depression indicating that major depression in the workplace likely occurs at a rate comparable to that in the general population (4\%). ${ }^{78}$ Major depression is one of the major causes of work disability. ${ }^{9}$ There are many evidences showing increased work absence related to depression..$^{10} \mathrm{~A}$ study found that compared with other mental disorders, depression-related impairment of work affected more employees, lasted longer, and had a higher recurrence rate. ${ }^{11}$ Another study found that depression was a major contributor to work loss and absence with effects surpassing almost all of the chronic medical disorder that they examined. ${ }^{12}$ These results show why depression, among other mental disorders, should be more highlighted in the workplace.

Managing the mental health of employees in small businesses (i.e., those with less than 50 employees) is exceedingly important, given that such workplaces are typically characterized by a poorer work environment. Workers with mental illnesses may be especially terrified by the possibility of losing their jobs because of their illness, and therefore attempt to hide their mental health problems. ${ }^{2,13}$ For this reason, physicians specializing in occupational and environmental medicine should employ diagnostic interviews or screening tests to help identify such hidden mental health problems.

The purpose of this article was to introduce a number of assessment tools for job stress and depressive disorders that can be employed in workplaces to examine mental health. We will in particular focus on those tools that have been validated in Korean and for which there are feasibility studies conducted in South Korea.

\section{JOB STRESS}

The National Institute for Occupational Safety and Health (NIOSH) defines "job stress" as a harmful physical/sentimental reaction that occurs when the job demands do not match the skills or resources of a worker. ${ }^{14}$ Methods of measuring such stress include self-evaluations of the number of objective stress sources, measuring physical reactions or how such reactions are interpreted, evaluations of individual differences in stress responses, and determining the presence of diseases that are attributable to stress. ${ }^{15}$ Because it is difficult to conduct a comprehensive assessment of various aspects of job stress reactions, multiple tools with different purposes might be employed in accordance with the traits of the individuals or working environment in question.

\section{National Institute for Occupational Safety and Health Job Content Questionnaire}

The NIOSH Job Content Questionnaire (NIOSH JCQ) ${ }^{16}$ was developed to solve the problems caused by using unverified tools or a mixture of multiple tools. This tool is based on an existing stress model and a vast amount of literature, thus making it generalizable to a number of occupational conditions. The tool has been validated in Korean, although the internal consistency for the subscales of resource control, routine activities, mental burden, and A-type characters appear low (Cronbach's $\alpha=0.26-0.66) .{ }^{17}$ However, for the other subscales, the internal consistency appears high (Cronbach's $\alpha=$ $0.71-0.86) .^{17}$

The NIOSH JCQ is based on a model of stress proposing that the work conditions or stress sources in workplaces can influence individuals' mental and physiological processes, and these acute responses in turn become causes of disease over time. ${ }^{16}$ While stress sources can cause acute responses, such responses can be mitigated by various personal traits, such as individuals' character or self-esteem, sources of social support, family relationships, marital status, and other factors outside of the workplace. These factors function as moderators of the acute responses among individuals exposed to the same stress factors. A total of 253 items are included in the questionnaire, including 13 subscales of psychological job stressors, 2 subscales of psychological stress reactions, and 3 subscales of social supports (Table 1). Items are answered using a variety of formats, including dichotomous (yes/no) or 4- or 5-point scales. When all of the items are used, the scale takes between 30 minutes and 1 hour to complete, which is a drawback for this tool. However, because each subscale is contained within a separate questionnaire, it is possible to administer them separately. The NIOSH JCQ is overall considered a good tool for use in managing level of personal stress. It can also be helpful for managing the mental health of work groups, as it can be used to compare the average of a certain group to the overall level as well as levels by gender, age, or workplace division.

\section{Karaseks Job Content Questionnaire}

The Karasek's Job Content Questionnaire ${ }^{18}$ was developed to measure the social and psychological characteristics in the workplace. It is based on the Karasek's demand-control model that explains the combination of job demand and control results in different degrees of stress-related risk, perceived strain, and active-passive behaviours in workplaces. ${ }^{18,19} \mathrm{Un}$ der this model, job strain is developed by high demand, low control, and low support. Therefore, these three factors consist of the three main subscales of decision latitude, psychological demands and mental workload, and social support. 
Table 1. Psychometric properties of the job stress rating scales

\begin{tabular}{|c|c|c|c|}
\hline \multirow{2}{*}{$\begin{array}{l}\text { Assessment } \\
\text { tool }\end{array}$} & \multicolumn{2}{|c|}{ Cronbach's a } & \multirow[b]{2}{*}{ Subscales and contents (number of items) } \\
\hline & $\begin{array}{l}\text { Original } \\
\text { version }\end{array}$ & $\begin{array}{l}\text { Korean } \\
\text { version }\end{array}$ & \\
\hline NIOSH JCQ & No comment & $0.26-0.86$ & $\begin{array}{l}\text { 1) Job stressor: Quantitative workload (11), Variance in workload (3), Cognitive demands (5), } \\
\text { Job control (16), Skill underutilization (3), Responsibility for people (4), Intragroup } \\
\text { conflict (8), Intergroup conflict (8), Role conflict (8), Role ambiguity (6), Job future } \\
\text { ambiguity (4), Employment opportunities (3), Physical environment (10) } \\
\text { 2) Social supports: Supervisor (4), Coworker (4), Family/friends (4) } \\
\text { 3) Psychological stress reactions: Job dissatisfaction (4), Depressive symptoms (20) }\end{array}$ \\
\hline Karasek JCQ & $0.66-0.81$ & $0.52-0.81$ & $\begin{array}{l}\text { Decision latitude (19), Psychological demands and mental workload (9), Social support (11), } \\
\text { Physical demands (5), Job insecurity (6) }\end{array}$ \\
\hline KOSS & No data & $0.51-0.82$ & $\begin{array}{l}\text { Physical environment (3), Job demand (8), Insufficient job conflicts (5), Interpersonal } \\
\text { conflict (4), Job insecurity (6), Lack of reward (6), Organizational system (7), } \\
\text { Occupational climate (4) }\end{array}$ \\
\hline JSS & $0.89-0.94$ & $0.90-0.95$ & $\begin{array}{l}\text { 1) Factor: Job pressure (10) Lack of organizational support (10) } \\
\text { 2) Calculation: Job stress Index (30), Job stress severity (29), Job stress frequency (30) }\end{array}$ \\
\hline
\end{tabular}

NIOSH JCQ: National Institute for Occupational Safety and Health Job Content Questionnaire, JCQ: Karasek's Job Content Questionnaire, KOSS: Korean Occupational Stress Scale, JSS: Job Stress Survey

Other aspects of work demands are assessed as well: two subscales of physical demands and job insecurity. The full recommended JCQ by Karasek has 49 items and five subscales (Table 1). ${ }^{18}$ The Cronbach's a for all scales under the Korean version was higher than 0.6 , except for job insecurity (0.53) and decision latitude $(0.52){ }^{20}$

The JCQ of the demand-control-support methods reflects psychological focus, and is probably more familiar among psychologists than sociologists. It describes classic psychological models, such as the behaviours for emotional psychological distress, psychosomatic illness, and behavioural changes for social situations. ${ }^{21}$ The presumption of the demand-control-support model is that health and well-being are determined by psychosocial experiences and treated through neuropsychological mechanisms. ${ }^{19}$

The JCQ has been used to analyze the job strain of workers so this scale highly contributed to confirming the relationship of cardiovascular disease, job-related musculoskeletal disease, smoking, drug abuse, alcohol poisoning, and pulse. ${ }^{21}$ Karasek's JCQ assesses work quality issues, thus allowing its application in social policy and work quantity issues, such as length of working hours, benefits, and wages. ${ }^{18}$ The scale also allows the testing of hypotheses on the economic issues of skill utilization and the social costs of market-based economic development. ${ }^{18}$ However, since personality orientation or measures of non-job stressors are not included, clinicians may want to supplement the instrument in these areas.

\section{Korean Occupational Stress Scale}

A number of assessment tools to measure job stress have been developed abroad, some of which have secured a high degree of reliability and relevance through years of refinement by trial and error. However, the items or phrasing of items in these instruments does not reflect the sociocultural characteristics of South Korea when translated directly from the original draft. ${ }^{22}$ Researchers devised the Korean Occupational Stress Scale (KOSS) in order to address this problem. ${ }^{23}$ More specifically, the KOSS was developed to identify the unique sources of job stress in South Korea and the finalized questions were included in the questionnaire. The KOSS is now most frequently used in measuring job strain in South Korea. ${ }^{13}$

The data for developing KOSS were obtained from the National Study for Development and Standardization of Occupational Stress (NSDSOS Project: 2002-2004). ${ }^{23}$ A total of 12,631 employees from a nationwide sample were administered. Two hundred fifty five items were initially collected from the most popular job stress measurement tools, such as NIOSH, JCQ, etc., and 44 items were derived from a qualitative study. Finally, 43 items under KOSS were retained for use in the final version of the KOSS (Cronbach's $\alpha=0.51-0.82$ ). ${ }^{23}$ A short form of the KOSS (KOSS-SF), comprising of only 24 items, were also developed. ${ }^{23}$

The KOSS assesses general job stress, meaning that the tool can be used in all workplaces. The instrument comprises 8 subscales (Table 1). The full version (43 items) takes 15-20 minutes to complete. Each item can be scored using a 4-point Likert scale (ranging from 1 to 4). Furthermore, items for which a higher score represents a lower level of job stress are reverse scored (i.e., from 4 to 1 ). The total score of each subscale is ultimately converted to a new score out of 100 . The score from each of the 8 subscales are converted in this manner, and the mean of the 8 subscale scores is taken as the total 
score. This total score can then be compared to the score distribution of the general population based on reference scores. The reference scores for male and female subjects differ. The scores from each subscale are converted using the following formula: [(actual score-the number of questions)/(the highest score that can be expected-the number of questions) $] \times 100$. Furthermore, the total job stress score is calculated using (sum of the converted scores from all 8 subscales) $/ 8$.

The KOSS does not assess personal traits or non-job sources of stress. Furthermore, it is unable to determine the severity of symptoms as a result of stress or be used for diagnosing workers for mental illness in workplaces. Therefore, this tool is best used along with other tools to provide a comprehensive picture of job stress.

\section{Job Stress Survey}

Job stress survey (JSS) is used to measure the generic sources of occupational stress that are encountered by workers who are employed in a wide variety of occupational settings. ${ }^{24}$ The JSS was developed based on previous research that examined the sources of stress specifically affecting high school teachers and law enforcement officers. ${ }^{24}$

Thirty items were designed to evaluate the perceived intensity (severity) and frequency of occurrence in working conditions (Table 1). First, subjects rate the severity of stress on each of the 30 JSS job stressors by using a 9-point scale, and these scores of severity are compared to a standard stressor event ("assignment of disagreeable duties") that is assigned a value in a 5-point scale. In previous research, this item under a stan- dard stressor event was rated near the middle of the range in the severity of job stress affecting both teachers and police officers. ${ }^{25}$ Second, subjects rate how frequently each of the 30 JSS stressors has occurred in the last six months. The number of days (from 0 to $9+$ days) on which each job stressor was experienced was rated to take into account the state-trait distinction that is important in anxiety assessment. Thus, JSS provides useful information on the perceived severity of 30 job stressor situations, and how frequently a worker experiences each job stressor event. The measures of severity and frequency represent individual subjective perception and the objective aspect of individual experience for each job stressor, respectively.

The overall scores of severity (JSS-S) and frequency (JSS-F) were calculated by summing up the scores for each individual JSS 30-item, and the sum of the cross-products of the JSS$\mathrm{S}$ and JSS-F scores yields the overall job stress index (JSS-X). These three indices are also computed to determine job pressure and organizational support subscales, which consist of 10 items, and were derived in the factor analysis of the total JSS 30 -items. ${ }^{24}$ The Korean version of the JSS was validated (Cronbach's $\alpha=0.90-0.95){ }^{26}$

\section{Application of stress assessment tools in the workplace}

Before the KOSS was developed, tools developed in foreign countries and translated into Korean, such as the NIOSH JCQ and Karasek's JCQ, were used. Such tools have been used worldwide for some time, and their reliability and relevance have been firmly established. However, because these tools do

Table 2. Characteristics of the job stress and depression rating scales

\begin{tabular}{|c|c|c|c|c|c|}
\hline Assessment tool & Rater & Number of items & Lead time & Interpretation of score & Major characteristics \\
\hline \multicolumn{6}{|l|}{ Job stress } \\
\hline NIOSH JCQ & Self-report & 253 & $30-60 \mathrm{~min}$ & Compared to reference value & International, broad scale \\
\hline Karasek JCQ & Self-report & 49 & $20 \min$ & Compared to reference value & $\begin{array}{c}\text { Karasek's strain model } \\
\text { to analyze job strain }\end{array}$ \\
\hline KOSS & Self-report & $43(24)$ & $15-20 \mathrm{~min}$ & Compared to reference value & Specific to Korean workers \\
\hline JSS & Self-report & 30 & No comment & $\begin{array}{l}\text { Integrating scores of severity } \\
\text { and frequency }\end{array}$ & $\begin{array}{l}\text { Measure of both subjective and } \\
\text { objective aspect }\end{array}$ \\
\hline \multicolumn{6}{|l|}{ Depression } \\
\hline HDRS & Clinician & $17(14-36)$ & $15-30 \mathrm{~min}$ & Remission $\leq 7$ & Multidimensional \\
\hline MADRS & Clinician & 10 & $15 \min$ & Remission $\leq 10$ & $\begin{array}{l}\text { More sensitive to symptom } \\
\text { changes than HDRS }\end{array}$ \\
\hline BDI & Self-report & 21 & No comment & Cut-off $=24$ & BDI-II reflects DSM-IV \\
\hline CES-D & Self-report & 20 & No comment & Cut-off $=25$ & $\begin{array}{l}\text { Nondiagnostic, community- } \\
\text { based assessment }\end{array}$ \\
\hline PHQ-9 & Self-report & 9 & $1-2 \mathrm{~min}$ & Cut-off $=10$ & Brief, reflects DSM-IV \\
\hline
\end{tabular}

NIOSH JCQ: National Institute for Occupational Safety and Health Job Content Questionnaire, JCQ: Karasek’s Job Content Questionnaire, KOSS: Korean Occupational Stress Scale, JSS: Job Stress Survey, HDRS: Hamilton Depression Rating Scale, MADRS: Montgomery-Åsberg Depression Rating Scale, BDI: Beck Depression Inventory, CES-D: Center For Epidemiologic Studies Depression Scale, PHQ-9: Patient Health Questionnaire-9 
not reflect the unique organizational culture or sociocultural features of South Korea, the KOSS has been deemed the most appropriate option for evaluating job stress in South Korea. It should be noted that while the KOSS is a good tool for measuring job stress in an objective manner, it cannot evaluate stress sources other than those in workplace, and does not consider the traits of the individual responding to the stress. Therefore, it is best used along with other tools appropriate for the situation. The NIOSH JCQ contains numerous items and therefore takes some time to complete. However, the scale comprises a number of different portions can be used selectively used according to the topic. It would seem to be a good option for evaluating stress among individuals as well as groups.

\section{DEPRESSION}

The assessment tools for depression can be divided into self-report scales and clinician-report scales (Table 2). Some of the advantages of self-report scales include their use of use and lack of need to train or educate administrators, thus making them cheaper. However, self-report scales rely on individuals' perceived or subjective feelings regarding symptoms, and the results can be influenced by factors such as age, education level, character, and gender. In contrast, clinician-rated scales can divorce the results from individuals' personal traits and better reflect the severity of the symptoms.

\section{Clinician-Rating Scales}

\section{Hamilton Depression Rating Scale}

The Hamilton Depression Rating Scale (HDRS) was developed to measure the severity of depression for use in research on major depressive disorder in the $1960 \mathrm{~s} .{ }^{27}$ Since then, its applications have expanded to include screening of depression, observation of its progression, and evaluation of the treatment efficacy. ${ }^{28}$ The HDRS was initially composed of 21 items. However, four of the items-those assessing "daily fluctuation of the mood," "depersonalization-derealization," "paranoia," and "obsession"-were found to be irrelevant to those with depression, thus decreasing the internal consistency of the instrument as a whole. ${ }^{28}$ These four items were thus removed, and the revised, 17-item version has since been widely used. ${ }^{29}$ The Korean validation study indicated that the Korean version of the HDRS (which contains 17 items) is a reliable and relevant tool that can be used in clinical contexts as well as for research purposes on patients with depression (Cronbach's $\alpha=0.76){ }^{30}$

As mentioned above, the most common version of the HDRS comprises 17 items, of which 9 are evaluated on a 5-point scale $(0-4)$ and 8 on a 3 -point scale $(0-2)$. The total score of the ques- tionnaire is 52 , with higher scores indicating more serious depression. A score of 7 or less is considered to indicate remission of depressive symptoms and a $50 \%$ or more decrease in HDRS scores is defined as to be responding to the depression treatment. $^{31}$

The HDRS takes 15-30 minutes to complete. One of its shortcomings is that the reliability of the administrator may differ depending on clinicians' expertise and interviewing skills. ${ }^{30,32}$ Furthermore, this instrument focuses more on the vegetative and somatic symptoms of depression rather than the actual core symptoms, while other critical aspects of depression such as recovery of self-confidence and returning to normal daily life are not very well reflected..$^{33}$ Despite these and other shortcomings, this instrument remains the most frequently used clinician-reported scale.

\section{Montgomery-Åsberg Depression Rating Scale}

Montgomery and Åsberg criticized the HDRS for only focusing on the diagnostic characteristics of depression and for lacking sensitivity to changes in symptoms caused by the treatment. To address these issues, they developed the Montgomery-Åsberg Depression Rating Scale (MADRS), which is more sensitive to symptom changes. ${ }^{34}$ The first step of the development of the MADRS involved extracting 17 items from the Comprehensive Psychopathological Rating Scale, an overall measure of psychiatric pathology. From these items, 10 showing higher correlations with treatment efficacy over a period of 4 weeks were selected as items for the MADRS. The Korean version of the MADRS has shown high internal consistency (Cronbach's $\alpha=0.79$ ), excellent inter-rater reliability, and comparable levels of relevance with the HDRS. ${ }^{35}$

All items are answered in terms of severity of symptoms within the last week using a seven-point scale (0-6). Answers with operational definitions are provided for scores $0,2,4$, and 6 , whereas scores 1,3 , and 5 reflect answers lying somewhere between those answers with operational definitions. For each item, a short definition of terms and guideline for questions are presented. The total score ranges from 0 to 60 , and higher scores indicating greater severity of depression. A total score of 10 or less is defined as remission, and score reduction of $50 \%$ or more is defined as a treatment response. ${ }^{36}$ Another study utilized a more specific and in-depth definition of remission, where an MADRS score of 5 points or less was considered to indicate "complete remission" and moreover no MADRS single item greater than 1 to define "symptom-free remission". ${ }^{37}$

Compared to the HDRS, the MADRS contains fewer items, and thus takes less time to complete (15 minutes). Furthermore, while the highest score for a single question item in the HDRS is 2 or 4 points, the highest score for each item on the 
MADRS is 6 points, making the scale somewhat more sensitive to changes in depressive symptoms. Furthermore, more of the items depend on subjects' perceptions of the symptoms rather than clinicians', making it easier to train observers to use the MADRS. This instrument is also more suitable for largescale clinical studies. However, the method is rather wanting in terms of assessment of residual symptoms such as anxiety or physical symptoms, thus making it rather unsuitable for use in South Korea, where depressive patients more commonly complain of physical symptoms. ${ }^{38}$

\section{Self-reporting scales}

\section{Beck Depression Inventory (BDI and BDI-II)}

The BDI was developed in 1961 and revised in 1979; later, in 1996, a second version-the BDI-II-was developed in order to better comply with the DSM-IV standards. ${ }^{39}$ The BDI is a self-report scale; thus, it does not require an observer to be trained in its administration. One of the other differences of this scale from other self-report scales is that it requires subjects to report using detailed statements, thereby allowing subjects to articulate their mental states more precisely. It was validated in South Korea, after which further studies helped to solidify its reliability and relevance (Cronbach's $\alpha=0.88$ ). ${ }^{40,41}$

The BDI uses 21 items to assess symptoms over the past week. Each item is evaluated on a scale ranging from 0 to 3 , which are then summed for a total score of $0-63$. The items for this method are divided into cognitive, emotional, motivational, and physical symptoms of depression, while a higher score indicates a more serious level of depression. The cutoff points used differ among researchers. In the West, scores of 10 or higher are considered indicative of depression. ${ }^{42}$ In South Korea, a number of studies have been conducted with somewhat higher cut-off points $\left(16^{43}\right.$ or $\left.21^{41}\right)$, as the average BDI score in South Korea is somewhat higher than that in Western countries. ${ }^{40,41,44}$

The DSM-IV revised the diagnostic criteria for depression; as these new diagnostic criteria complied with only 6 of the previous 9 symptoms measured by the BDI, the BDI was redesigned as the BDI-II in $1996 .^{45}$ The BDI-II does not differ from the BDI in terms of the number of items or the scoring method. However, the evaluation period was changed from one week to two weeks prior to the survey. Furthermore, in accordance with the new diagnostic criteria for depression, some of the items were re-phrased or completely altered. The Korean version of the BDI-II was also introduced and has proven to have excellent reliability and relevance (Cronbach's $\alpha=0.83) .{ }^{44}$ The validation study of the Korean version, a score of 22 was suggested as the cut-off point for depression. ${ }^{44}$

The BDI is not only helpful for evaluating the efficacy of treatment, but also a tool for screening depression in other ordinary studies or selecting depressive subjects for studies. However, as the results reflect subjects' subjective feelings about their depression, the results can be influenced by subjects' age, education level, gender, or other personal traits, which is a limitation of this instrument. ${ }^{46}$ Furthermore, the ratio of patients who exhibit a higher score on the BDI but exhibit no symptoms or ultimately are found to have other disorders remains high. Therefore, a high score on this scale does not constitute a depression diagnosis. ${ }^{46}$

\section{Center for Epidemiologic Studies Depression Scale}

The Center for Epidemiologic Studies Depression scale (CESD) was initially developed by Radloff et al. ${ }^{47}$ in 1977 . While other self-report scales were developed as tools for diagnosing depression, or assessment of severity of depression, this scale was developed for use in the Community Mental Health Assessment Survey of the 1970s. This scale is characterized by its exceedingly concise questions and ability to accurately distinguish depressed individuals from non-depressed individuals in the general population; furthermore, it is a good method of measuring the severity of depression based on the duration of having a symptom, it is a good tool for a community-wide epidemiological studies. Currently, this scale is being used as a tool to compare the prevalence of depressive symptoms between countries, genders, age groups, etc. Other Japanese studies have applied it to the workplace. ${ }^{48}$ Several Korean versions of the CES-D have been separately validated. These disparate Korean versions were then compared and used to develop a unified Korean CES-D in 2001 (Cronbach's $\alpha=0.89){ }^{49}$

The CES-D assesses symptoms experienced within the past week. The scale comprises 20 items in total, with a total score ranging from 0 to 63 . Higher total scores reflect more serious depressive symptoms. The tool comprises both negative items, such as "depressive mood," and positive items, such as "I am happy" or "I enjoyed life"; this was to help break the typical pattern of depression measurement tools and investigate the positive domain. In the West, a total score of 16 was defined as highly probable depression and 25 as clear depression. ${ }^{50}$ However, research in Korea has suggested that a score of 21 can be used for screening probable depression among the general population and 25 for a diagnosis of depression. ${ }^{51}$

\section{Patient Health Questionnaire 9}

The Patient Health Questionnaire (PHQ) was initially developed in 1999 as a self-report scale for use in the diagnostic process of several mental diseases commonly found in primary care contexts. Among its versions, the PHQ-9 is a 9-item scale specifically designed to diagnose major depressive disorders 
according to the DSM-IV depression diagnosis criteria..$^{52}$ The Korean version of the PHQ-9 has been validated, and shows good reliability and relevance (Cronbach's $\alpha=0.86$ ). ${ }^{53}$

The PHQ- 9 comprises 9 items, and each of the items is rated using a 4-point (i.e., 0-3) scale. The total score ranges from 0 to 27 , with higher scores indicating a more serious case of depression. Kroenke et al. ${ }^{52}$ suggested a cut-off score of 10 , although his study indicated that a score of 9 had the highest sensitivity (95\%) and specificity (84\%). This makes the cut-off easier to remember and apply to clinical contexts. In South Korea, 10 has been suggested as the cut-off, ${ }^{54}$ although among the Korean elderly population, 5 may be the optimal cut-off. ${ }^{53}$

The PHQ-9 appears to be an appropriate tool for use in actual clinical contexts and diagnosis, as it has fewer items than most depression scales and thus takes less time to complete. Another advantage of this tool is that it can be used for both screening and diagnosis, as well as for evaluating subjects' ability to perform their daily life routines/occupational functions or their severity of depressive symptoms. A higher score on this scale has been found to relate to higher severity and duration of major depressive disorder, usage rate of medical institutions, and degradation of functions. ${ }^{38}$

\section{Application of depression assessment tools in workplaces}

Self-report scales are appropriate for use in screening for depressive disorders, given their ease of use and the fact that they do not require separate training. As we discussed in this article, the BDI, BDI-II, CES-D, and PHQ-9 are all helpful in this regard (Table 2). However, these tools differ from each another and possess their own advantages and disadvantages. Therefore, the exact tool needed may depend on the situation. For instance, the BDI-II, CESD-R, and PHQ-9 rely on the diagnostic criteria for depression of the DSM-IV, and therefore are useful in epidemiologic studies. In contrast, the CES-D, which is suited for the general population, might be used on elderly workers. The PHQ-9 comprises only 9 items and can be answered in 1-2 minutes, making it a good option for a busy clinical environment or examinations for screening purposes. In contrast, clinician-reported scales are best used to evaluate depression objectively, as they can discount the contributions of personal traits and subjective feelings during evaluations of depression (which self-report scales cannot do) (Table 2). However, clinician-reported scales typically take 15-30 minutes or longer to complete, making it necessary for the administrator to be trained for this purpose or in administering structured interviews. Therefore, such scales cannot easily be used for screening purposes. The standardized scales used in South Korea include the HDRS and MADRS. Of these two, the HDRS would be the standard. However, it still takes $15-30$ minutes to complete and is sensitive to the skills of the administrator. In contrast, the MADRS contains fewer items than does the HDRS, takes less time, does not rely on the education of the administrator as much, and has a higher maximum score for each question, thus making it more sensitive to the changes in symptoms. The MADRS is perhaps best used as a secondary diagnostic tool following a selfreport screening scale; alternatively it can be used to measure the severity of depressive disorders among workers.

\section{CONCLUSION}

We discussed a number of assessment tools for job stress and depression. For job stress, foreign tools such as Karasek's JCQ and the NIOSH JCQ were translated into Korean and predominantly used before the development of the KOSS. However, given the unique sociocultural and organizational characteristics of South Korea, the KOSS is perhaps most appropriate for use in this country. The assessment tools for depression can be divided into clinician-reported and self-reported scales. Considering the fact that evaluations should be completed in a short amount of time in the workplace, selfreport scales, such as the BDI, CES-D, and PHQ-9, would be appropriate for screening, given that they contain fewer items and do not require trained administrators. On the other hand, clinician-reported scales such as the HDRS or MADRS contain more items and take longer to complete. However, as they are capable of evaluating depression in a more objective manner, it would be helpful for diagnosing depression as a secondary test after the initial screening or for managing patients who are diagnosed with depression in the workplace.

\section{REFERENCES}

1. Westgaard RH, Winkel J. Occupational musculoskeletal and mental health: significance of rationalization and opportunities to create sustainable production systems - a systematic review. Appl Ergon 2011;42: 261-296.

2. Choi KS, Kang SK. Occupational psychiatric disorders in Korea. J Korean Med Sci 2010;25(Suppl):S87-S93.

3. Shin IJ. Major industrial accidents in Korea: the characteristics and implication of statistics 1996-2011. Process Safety Progress 2013;32:9095.

4. Park JN, Han MA, Park J, Ryu SY. Prevalence of depressive symptoms and related factors in Korean employees: the third Korean working conditions survey (2011). Int J Environ Res Public Health 2016;13:424.

5. Rhee KY, Choe SW. Management system of occupational diseases in Korea: statistics, report and monitoring system. J Korean Med Sci 2010; 25(Suppl):S119-S126.

6. Cho MJ, Chang SM, Lee YM, Bae A, Ahn JH, Son J, et al. Prevalence of DSM-IV major mental disorders among Korean adults: a 2006 National Epidemiologic Survey (KECA-R). Asian J Psychiatr 2010;3:26-30.

7. Goldberg RJ, Steury S. Depression in the workplace: costs and barriers to treatment. Psychiatr Serv 2001;52:1639-1643.

8. Waraich P, Goldner EM, Somers JM, Hsu L. Prevalence and incidence studies of mood disorders: a systematic review of the literature. Can J 
Psychiatry 2004;49:124-138.

9. Stewart WF, Ricci JA, Chee E, Hahn SR, Morganstein D. Cost of lost productive work time among US workers with depression. JAMA 2003;289:3135-3144.

10. Kessler RC, Frank RG. The impact of psychiatric disorders on work loss days. Psychol Med 1997;27:861-873.

11. Dewa CS, Goering P, Lin E, Paterson M. Depression-related short-term disability in an employed population. J Occup Environ Med 2002;44: 628-633.

12. Grzywacz J, Ettner SL. Lost time on the job: the effect of depression versus physical health conditions. Eco Neurosci 2000;2:41-46.

13. Cho JJ, Kim JY, Chang SJ, Fiedler N, Koh SB, Crabtree BF, et al. Occupational stress and depression in Korean employees. Int Arch Occup Environ Health 2008;82:47-57.

14. Nielsen MB, Bergheim K, Eid J. Relationships between work environment factors and workers' well-being in the maritime industry. Int Marit Health 2013;64:80-88.

15. Kawada T, Otsuka T. Relationship between job stress, occupational position and job satisfaction using a brief job stress questionnaire (BJSQ). Work 2011;40:393-399.

16. Hurrell JJ Jr, McLaney MA. Exposure to job stress--a new psychometric instrument. Scand J Work Environ Health 1988;14(Suppl 1):27-28.

17. Lee BI. Gender differences in job stress and depression of service workers. Korean J Occup Health Nurs 2009;18:232-241.

18. Karasek R, Brisson C, Kawakami N, Houtman I, Bongers P, Amick B. The Job Content Questionnaire (JCQ): an instrument for internationally comparative assessments of psychosocial job characteristics. J Occup Health Psychol 1998;3:322-355.

19. Karasek R. The political implications of psychosocial work redesign: a model of the psychosocial class structure. Int J Health Serv 1989;19: 481-508.

20. Eum KD, Li J, Jhun HJ, Park JT, Tak SW, Karasek R, et al. Psychometric properties of the Korean version of the job content questionnaire: data from health care workers. Int Arch Occup Environ Health 2007;80: 497-504.

21. Karasek R, Baker D, Marxer F, Ahlbom A, Theorell T. Job decision latitude, job demands, and cardiovascular disease: a prospective study of Swedish men. Am J Public Health 1981;71:694-705.

22. Park SG, Min KB, Chang SJ, Kim HC, Min JY. Job stress and depressive symptoms among Korean employees: the effects of culture on work. Int Arch Occup Environ Health 2009;82:397-405.

23. Chang SJ, Koh SB, Kang D, Kim SA, Kang MG, Lee CG, et al. Developing an occupational stress scale for Korean employees. Korean J Occup Environ Med 2005;17:297-317.

24. Vagg PR, Spielberger CD. The Job Stress Survey: assessing perceived severity and frequency of occurrence of generic sources of stress in the workplace. J Occup Health Psychol 1999;4:288-292.

25. Spielberger CD, Vagg PR. Professional Manual for the Job Stress Survey (JSS). Odessa, FL: Psychological Assessment Resources; 1994.

26. Kim K, Park C, Chon KK. Development of the Korean job stress survey: study 1. Korean J Health Psychol 2004;9:415-440.

27. Hamilton M. A rating scale for depression. J Neurol Neurosurg Psychiatry 1960;23:56-62.

28. Williams JB. Standardizing the Hamilton Depression Rating Scale: past, present, and future. Eur Arch Psychiatry Clin Neurosci 2001;251 (Suppl 2):II6-II12.

29. Hamilton M. Development of a rating scale for primary depressive illness. Br J Soc Clin Psychol 1967;6:278-296.

30. Yi JS, Bae SO, Ahn YM, Park DB, Noh KS, Shin HK, et al. Validity and reliability of the Korean version of the Hamilton Depression Rating Scale (K-HDRS). J Korean Neuropsychiatr Assoc 2005;44:456-465.

31. Zimmerman M, Chelminski I, Posternak M. A review of studies of the Hamilton Depression Rating Scale in healthy controls: implications for the definition of remission in treatment studies of depression. J Nerv Ment Dis 2004;192:595-601.
32. Bagby RM, Ryder AG, Schuller DR, Marshall MB. The Hamilton Depression Rating Scale: has the gold standard become a lead weight? Am J Psychiatry 2004;161:2163-2177.

33. Zimmerman M, McGlinchey JB, Posternak MA, Friedman M, Attiullah N, Boerescu D. How should remission from depression be defined? The depressed patient's perspective. Am J Psychiatry 2006;163:148150.

34. Montgomery SA, Asberg M. A new depression scale designed to be sensitive to change. Br J Psychiatry 1979;134:382-389.

35. Ahn YM, Lee KY, Yi JS, Kang MH, Kim DH, Kim JL, et al. A validation study of the Korean-version of the Montgomery-Asberg depression rating scale. J Korean Neuropsychiatr Assoc 2005;44:466-476.

36. Trivedi MH. Tools and strategies for ongoing assessment of depression: a measurement-based approach to remission. J Clin Psychiatry 2009; 70(Suppl 6):26-31.

37. Favre P. Clinical efficacy and achievement of a complete remission in depression: increasing interest in treatment with escitalopram. Encephale 2012;38:86-96.

38. Carmody TJ, Rush AJ, Bernstein I, Warden D, Brannan S, Burnham D, et al. The Montgomery Asberg and the Hamilton ratings of depression: a comparison of measures. Eur Neuropsychopharmacol 2006;16:601-611.

39. Dozois DJ, Dobson KS, Ahnberg JL. A psychometric evaluation of the Beck Depression Inventory-II. Psychol Assess 1998;10:83-89.

40. Lee M, Lee Y, Park S, Sohn C, Jung Y, Hong S, et al. A standardization study of beck depression inventory (I): Korean version (K-BDI): reliability land factor analysis. Korean J Psychopathol 1995;4:77-95.

41. Hahn H, Yum T, Shin Y, Kim K, Yoon D, Chung K. A standardization study of Beck Depression Inventory in Korea. J Korean Neuropsychiatr Assoc 1986;25:487-500.

42. Lasa L, Ayuso-Mateos JL, Vazquez-Barquero JL, Diez-Manrique FJ, Dowrick CF. The use of the Beck Depression Inventory to screen for depression in the general population: a preliminary analysis. J Affect Disord 2000;57:261-265.

43. Lee Y, Song J. A study of the reliability and the validity of the BDI, SDS, and MMPI-D scales. Korean J Clin Psychol 1991;10:98-113.

44. Lim S, Lee E, Jeong S, Kim H, Jeong C, Jeon T, et al. The validation study of Beck Depression Scale 2 in Korean version. Anxiety Mood 2011;7: 48-53.

45. Beck AT, Steer RA, Brown GK. BDI-II. Beck Depression Inventory Second Edition. Manual. San Antonio: Psychological Corporation; 1996.

46. Domken M, Scott J, Kelly P. What factors predict discrepancies between self and observer ratings of depression? J Affect Disord 1994;31:253-259.

47. Radloff LS. The CES-D scale a self-report depression scale for research in the general population. Appl Psychol Meas 1977;1:385-401.

48. Tsutsumi A, Kayaba K, Theorell T, Siegrist J. Association between job stress and depression among Japanese employees threatened by job loss in a comparison between two complementary job-stress models. Scand J Work Environ Health 2001;27:146-153.

49. Chon K, Choi S, Yang B. Integrated adaptation of CES-D in Korea. Korean J Health Psychol 2001;6:59-76.

50. Demirchyan A, Petrosyan V, Thompson ME. Psychometric value of the Center for Epidemiologic Studies Depression (CES-D) scale for screening of depressive symptoms in Armenian population. J Affect Disord 2011;133:489-498.

51. Cho MJ, Kim KH. Use of the Center for Epidemiologic Studies Depression (CES-D) Scale in Korea. J Nerv Ment Dis 1998;186:304-310.

52. Kroenke K, Spitzer RL, Williams JB. The PHQ-9: validity of a brief depression severity measure. J Gen Intern Med 2001;16:606-613.

53. Han C, Jo SA, Kwak JH, Pae CU, Steffens D, Jo I, et al. Validation of the Patient Health Questionnaire-9 Korean version in the elderly population: the Ansan Geriatric study. Compr Psychiatry 2008;49:218-223.

54. Park S, Choi H, Choi J, Kim K, Hong J. Reliability and validity of the Korean version of the Patient Health Questionnaire-9 (PHQ-9). Anxiety Mood 2010;6:119-124. 